\title{
ASSESSMENT
}

\section{Developing Undergraduate Scientists by Scaffolding the Entry into Mentored Research}

\author{
Farron McIntee, Wayne State University \\ Kendra R. Evans, University of Detroit Mercy \\ Jeanne M. Andreoli, University of Detroit Mercy and Marygrove College \\ Abigail J. Fusaro, Marygrove College \\ Melanie Hwalek, SPEC Associates \\ Ambika Mathur, Andrew L. Feig, Wayne State University
}

\begin{abstract}
For many college students, joining a research group is a critical step toward developing strong mentor-mentee relationships that help shape their science identities and research self-efficacy. ReBUILDetroit, a program that seeks to diversify the biomedical research workforce, uses a scaffolded process to help its scholars transition into research. The first-year curriculum includes a research methods course and a course-based undergraduate research experience that prepare ReBUILDetroit Scholars for entering a research group. Curricular and cocurricular elements prepare scholars for faculty interactions and diminish barriers that might otherwise prevent diverse students from obtaining these research experiences. The program facilitates research placements through student coaching and speed-pairing events. Quantitative and qualitative data on the scholars show strong perceived gains in science identity, enhanced research self-efficacy, and greater research preparedness.
\end{abstract}

Keywords: diversity, inclusion, mentorship, science identity, self-efficacy

doi: $10.18833 /$ spur/2/1/5

\section{Overview of the Challenge}

Research experiences and the mentor-mentee relationships involved are of particular importance for career progression of trainees in biomedical disciplines (Brink 1995; Cupples 1999; Eagan et al. 2013; Lopatto 2007; Moed
2012). Students who participate in undergraduate research receive multiple layers of mentorship as a result of joining research groups. Positive relationships tend to lead students to persist through the challenges and transitions of their undergraduate careers, whereas less supportive relationships lead students to self-select out of the field (Linn et al. 2015; Lopatto 2007). For undergraduates, the process of identifying suitable career mentors is often arbitrary and challenging (Hurtado et al. 2009). In the case of students from underrepresented backgrounds, this challenge is even greater because, in many cases, the faculty come from very different backgrounds, do not look like them, and may be difficult to approach (Prunuske et al. 2013; Prunuske et al. 2016). The process of helping early undergraduates find research mentors in their discipline must become more intentional if the diversity of the scientific workforce is to be achieved (Boyd and Wesemann 2009; Committee on Underrepresented Groups and the Expansion of the Science and Engineering Workforce Pipeline 2011; Packard 2015; Ramirez 2012).

Studies on the impact of undergraduate research have struggled to articulate the contribution of the mentor-mentee relationships to student development, degree completion, and career progression (Packard 2015; Thiry and Laursen 2011). These relationships are complex and multifaceted, often including additional parties such as graduate students and research group members that enrich the experience but also make it more difficult to control (Aikens et al. 2017; Aikens et al. 2016; Pfund et al. 2016). Graduate programs rarely include training on how to be a good mentor; mentoring skills are most often learned informally by 
observing one's own mentors (Handelsman et al. 2009; Sorkness et al. 2013). Likewise, incoming college students may not be ready to enter productive mentoring relationships and often little is done to help students understand the bidirectionality of mentoring (Branchaw, Pfund, and Rediske 2010). How are students prepared to be receptive mentees? How are faculty and bench mentors trained to be more inclusive? Is there intention in how mentors are paired with mentees? Finally, how are successful mentoring relationships assessed and quantified in order to identify best practices and enhance self-awareness in both mentors and mentees so that they build the productive relationships that lead to career success? These are some of the questions that ReBUILDetroit attempts to address in preparing the undergraduate students in this program for careers in biomedical research.

\section{ReBUILDetroit}

ReBUILDetroit is a National Institutes of Health (NIH)funded collaboration among the University of Detroit Mercy, Marygrove College, and Wayne State University (WSU), designed to enhance diversity in the biomedical research workforce by improving STEM persistence; four- and six-year graduation rates; and entry into graduate and professional programs of students underrepresented in STEM disciplines based on gender, race, or socioeconomic status (Andreoli et al. 2017). The three ReBUILDetroit institutions are located in the urban core of Detroit within a few miles of each other and serve as the backbone of higher education within the city. Detroit
Mercy and Marygrove are primarily undergraduate institutions with relatively small student enrollment and low student-to-faculty ratios, whereas Wayne State is a large, public urban research university. Although the three institutions draw more than 85 percent of their undergraduates from the Detroit metropolitan region, with a high percentage of nonresidential students, each institution tends to attract a different population of students based on its mission and culture.

The students exemplify diverse, urban, postsecondary student populations in the twenty-first century. Many take nonlinear pathways through college and work while in school to pay their bills (Kuh et al. 2006; Malcom and Feder 2016). Finding time to participate in undergraduate research is often not a top priority due to financial pressures. Therefore, one critical aspect of the program is that the ReBUILDetroit Scholars receive a stipend if they remain in good academic standing. This support makes room in their schedules for cocurricular activities, like research, and facilitates a transition to academically relevant employment opportunities, such as paid internships and laboratory positions. Across the consortium, there are approximately 40 to 50 scholars per year, limited by the amount of financial aid that can be targeted to this program through either grant or institutional resources. Table 1 shows the distribution of ReBUILDetroit Scholars from 2015 through 2017 based on consortium institution, gender, socioeconomic status (as determined by Pell Grant eligibility), and racial/ethnic classification.

TABLE 1. Demographics of ReBUILDetroit Scholars 2015-2017

\begin{tabular}{|c|c|c|c|c|c|}
\hline Cohort & Institution & $\begin{array}{c}\text { Number } \\
\text { of scholars }\end{array}$ & $\begin{array}{c}\text { Pell eligible } \\
(\%)\end{array}$ & $\begin{array}{c}\text { UR }^{\mathrm{b}} \\
(\%)\end{array}$ & $\begin{array}{c}\text { Female } \\
(\%)\end{array}$ \\
\hline \multirow{2}{*}{2015} & WSU & 17 & 53 & 65 & 76 \\
& UDM & 26 & 81 & 62 & 77 \\
\hline \multirow{2}{*}{2016} & MG & 9 & 63 & 100 & 66 \\
\hline \multirow{2}{*}{2017} & WSU & 13 & 46 & 62 & 69 \\
& UDM & 23 & 78 & 78 & 50 \\
\hline & MG & 6 & 83 & 67 & 73 \\
& WSU & 15 & 27 & 67 & 67 \\
\hline
\end{tabular}

Note $: \mathrm{MG}=$ Marygrove College, $\mathrm{UDM}=$ University of Detroit Mercy, WSU = Wayne State University

aNumber of ReBUILDetroit Scholars reported at the beginning of the academic year and before the speedpairing process; some scholars did not participate in the speed-pairing process depicted in Figure 3.

bUR: Underrepresented groups. Based on NIH-NOT-OB-15-053, which includes only race and ethnicity. New guidance from NIH is forthcoming in NIH-NOT-18-122 that may affect future reporting, as it includes a broader definition of underrepresented groups.

'In August 2017, Marygrove College announced that it would close its undergraduate programs after the fall 2017 semester. All Marygrove ReBUILDetroit Scholars transferred to University of Detroit Mercy to continue their education and finish the ReBUILDetroit program. 
FIGURE 1. Schematic Diagram of the First-Year Activities for ReBUILDetroit Scholars

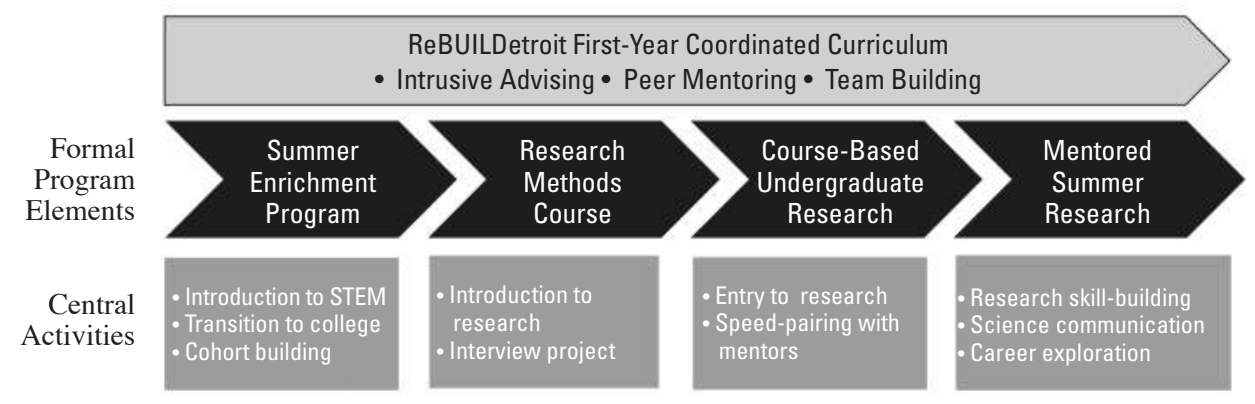

\section{Assessment Methods}

\section{Human Subjects Work}

All data collection was performed under the supervision of the WSU and Detroit Mercy Institutional Review Boards (WSU Protocol No. 1408013301, Detroit Mercy Protocol No. 1415-07). Data were collected, cleaned, and analyzed by staff from SPEC Associates and reported to program staff in deidentified, aggregated formats. ReBUILDetroit Scholars received financial support in the form of tuition scholarships and research stipends supported in part by NIH grant (RL5-GM118981). Participation in surveys and focus group interviews regarding their experience in the program was voluntary. Students completed end-ofsummer-research surveys in a group setting just prior to participation in a focus group interview. The only incentive students received for participating in the evaluation process was lunch provided on the day of data collection.

\section{Student Surveys and Focus Groups}

Data on student perceptions of their research experiences and preparation for research was collected using sections from the Undergraduate Research Student Self-Assessment (URSSA) instrument (Weston and Laursen 2015). The instrument followed the exact pattern of responses as in the original URSSA instrument. The only adaptation was to remove items irrelevant to students just starting their research experiences (e.g., writing research articles, winning an award for their research, or presenting a paper that was published in an academic journal).

URSSA was designed so that students respond to survey items in terms of their perceptions of gain or ratings of quality. For each survey item, students were asked to think about their most recent research experience and to indicate how much they had gained (with regard to thinking and working like a scientist, personal achievements related to research work, improvement of research skills); to indicate how much they had done (related to overall research experience and changes in attitudes or behaviors as a researcher); or to rate their experience (with research and mentoring). Weston and Laursen (2015) examined the reliability of the items comprising the first four of these dimensions and found that they had more than adequate reliabilities as measured by coefficient alpha.

Responses to the URSSA items were arranged on a 5-point Likert-type scale, ranging from "no gains" (1) to "great gains" (5). Responses on the items within each dimension were summed to create a scale score. Because the number of items and number of response options varied across dimensions, standardized scale scores were created so that each scale would range from 0 to 100 percent. The number of usable responses varied by scale as some responses had to be discarded if a survey response within the scale was insufficient.

Two-hour focus groups were conducted with scholars after they completed their summer research in 2017. For these interviews, students were separated by both institution and cohort year. Thus, a total of six focus groups was conducted, representing the three partner institutions (University of Detroit Mercy, Marygrove College, and Wayne State University) with a total of 24 students participating from the first cohort (2015) and 19 students participating from the second cohort (2016).

\section{Results}

\section{Program Design and Implementation}

Studies on underrepresented and socioeconomically disadvantaged groups often point to early college experiences that lead these students to leave STEM majors (Hurtado et al. 2008; Hurtado et al. 2017; Wilson et al. 2015). Therefore, ReBUILDetroit focuses on the first-year experience as an important transition period that will benefit scholars the most, setting the students on a path to college success and STEM degree attainment (see Figure 1). The integrated experience integrates academic expectations, instills a positive science identity and self-efficacy through a combination of mentorship and coursework, and transitions the students from simple consumers of knowledge to creators of knowledge, or researchers.

ReBUILDetroit Scholars across institutions and disciplines begin their first academic year in the program, 
whether as first-year or transfer students, by enrolling in a research methods course. This class is part of a coordinated first-year curriculum that also includes a coursebased undergraduate research experience (CURE) that is discipline-specific (biology, chemistry, health disparities; see Figure 1). The research methods course is designed to incorporate elements of Branchaw, Pfund, and Rediske's Entering Research (2010). ReBUILDetroit Scholars are introduced to some essential elements of research, including searching and reading the scientific literature, laboratory record keeping, and methods for selecting lines of research. Another important objective of the course is to develop students' self-efficacy in communicating and networking with research scientists. A faculty interview project helps break down barriers that prevent undergraduate students, particularly those from underrepresented groups, from effectively finding high-quality mentors (Hurtado et al. 2011). This interview serves as the first step in pairing scholars with research mentors for their summer research experience. A unique aspect of the program is that ReBUILDetroit Scholars are permitted and even encouraged to consider research mentors across the consortium. As a result, scholars have the opportunity to select faculty interviewees from a diverse array of disciplines, laboratory types, and institutions; these types of partnerships are essential for providing broad access to high- quality undergraduate research experiences (Boyd and Wesemann 2009).

Scholars are coached during preparation for their faculty interviews with scaffolded assignments: reading and summarizing a research paper by the prospective research mentor, developing questions to ask mentors about research interests and professional background, developing short biographical sketches of themselves to share with the mentors, and crafting emails to send to them. An additional topic of conversation is standard interview etiquette (proper attire, resume preparation, etc.). Faculty mentors affiliated with the ReBUILDetroit program are reminded by program staff that ReBUILDetroit Scholars will be requesting meetings to ensure good mentor response rates, especially between institutions. Following the interviews, the scholars prepare a brief summary of the meeting and reflect on what they have learned during this experience.

The second step is a speed-pairing event between the scholars and potential research mentors, occurring during the second semester of the academic year as a cocurricular activity alongside the CURE class. Speed-pairing has been used in a few settings to help mentees identify mentors (Guse et al. 2016; Kurré et al. 2014) but seldom implemented at the undergraduate level and never with advanced training of the mentees. By creating a formalized process for pairing, scholars are placed on a more equitable footing with respect to finding a research mentor. The coaching that occurs prior to the pairing events
FIGURE 2. Images of ReBUILDetroit Scholars and Faculty Mentors during Speed-Pairing Event

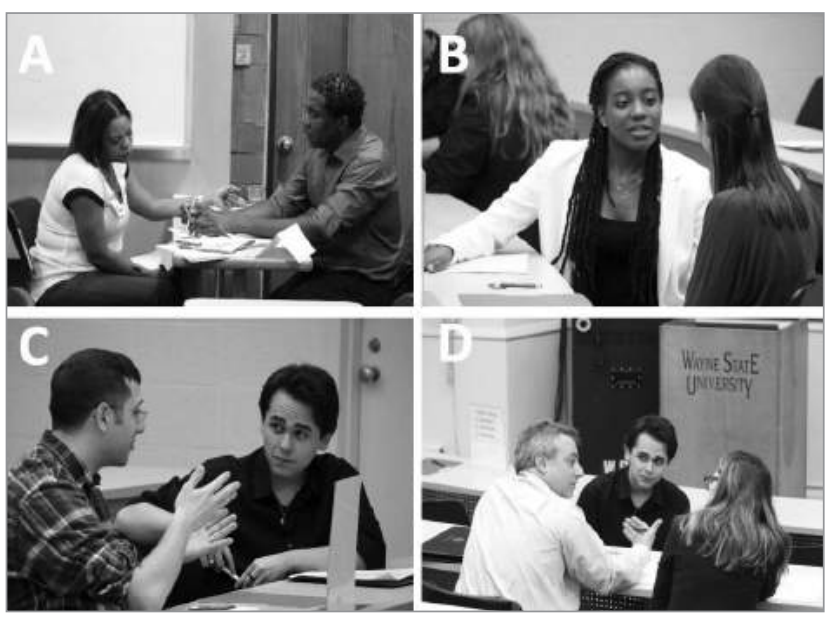

A: Jamillah Douthet interviews with psychology professor Harold Greene at University of Detroit Mercy.

B: Nailah Henry interviews with psychology assistant professor Jessica Damoiseaux at WSU.

C: Kody Whisnant interviews with biological sciences assistant professor Jared Schrader at WSU.

D: Kody Whisnant and Madeleine Reardon interview with chemistry professor Andrew Feig at WSU.

explicates some of the expectations of which scholars may not be aware that may affect some scholars as they seek appropriate research placements.

To prepare for speed-pairing, scholars review mentors' research agendas and submit a list of mentors whose research is of interest to them. The lists are compiled and used to match student and faculty interests during the pairing event. Prior to the speed-pairing event, scholars are informed of the mentors they will interview. They then apply the skills learned during the research methods course to review the work of the prospective mentors, which increase the scholars' confidence during the interviews. During the speed-pairing event, scholars participate in three or four 20-minute interviews, mostly one-on-one but occasionally in pairs (see Figure 2). Following the speed-pairing interviews, mentors rank the scholars with whom they have met and indicate their willingness to accept them into their research groups; likewise, the scholars rank their interest in working with specific mentors following the interviews.

The mentor-mentee pairing committee, composed of ReBUILDetroit faculty and staff, facilitates the event and coordinates the summer research placements. In addition to mentor and scholar ranking, other criteria are considered when placing scholars in a laboratory. For example, the goal is to place two scholars with each mentor to provide peer-level support for each student. Student success coordinators who work one-on-one with each 
scholar throughout the year are able to provide valuable insights regarding each scholar, such as level of academic preparedness, professional goals, and access to transportation if research at another institution is considered. ReBUILDetroit faculty facilitating the speed-pairing also are experienced researchers from a variety of biomedical disciplines and are able to assess both the scope of the research performed by each mentor and the academic experience of each scholar. The goal is to ensure that each scholar is prepared with the necessary skills, knowledge, and disposition to acclimate easily to the mentor's research group. This intentional coaching over the academic year and during the speed-pairing process ideally pairs the scholar and a research mentor with whom the scholar will continue to work throughout the undergraduate program. Although most of the scholars from WSU stay at WSU, about one-half of the scholars from Detroit Mercy and Marygrove come to WSU for their research experiences (see Figure 3).

Once the research placement process is complete, the research mentors are invited to participate in a two-hour mentor training workshop based on the curricula developed by the National Research Mentoring Network (Pfund et al. 2016; Pfund et al. 2015). Bench mentors, graduate students, and postdoctoral trainees who may serve as daily contacts for the ReBUILDetroit Scholars also are encouraged to attend. The workshop curriculum includes content on implicit bias, effective communication, and mentoring agreements that can be used to convey expectations for both mentor and mentee. Finally, the mentor-mentee relationship is monitored throughout the summer research experience via brief biweekly online surveys, which are reviewed upon receipt by student success coordinators and faculty on the mentor-mentee pairing committee. The survey feedback allows for rapid intervention if any engagement or interpersonal issues develop.

\section{Student Outcomes}

ReBUILDetroit is designed to help seamlessly transition students into mentored research through a series of phased activities that build their science identities and research self-efficacy over the course of the students' first year. In the research methods course, scholars learn how research problems are identified and how to select suitable approaches to examining them. CUREs provide a protective environment in which to explore solving a problem with a group of relative novices. The speed-pairing process is intended to provide both mentor and mentee with some agency related to entering the mentor-mentee relationship and to improve the likelihood that students have a positive transition to mentored research that builds their self-identity as scientists (Chang et al. 2011). As students build that self-efficacy and science identity, it is hypothesized that they will become better prepared for their first mentored research experiences, be able to persist through difficult parts of the curriculum, and be more likely to graduate with STEM degrees.

All eligible ReBUILDetroit Scholars ( $\mathrm{N}=123$ ) participated in mentored summer research during summer 2016 and summer 2017. An adapted version of the Undergraduate Research Student Self-Assessment (URSSA) questionnaire was used to measure scholars' perceptions of gains from their undergraduate research experiences (Weston and Laursen 2015). Dimensions of URSSA relevant to assess-

FIGURE 3. Sankey Diagram Showing the Relationship between Home Institution and Summer Research Institution for 2016 and 2017 Summer Research Experiences Resulting from the SpeedPairing Events

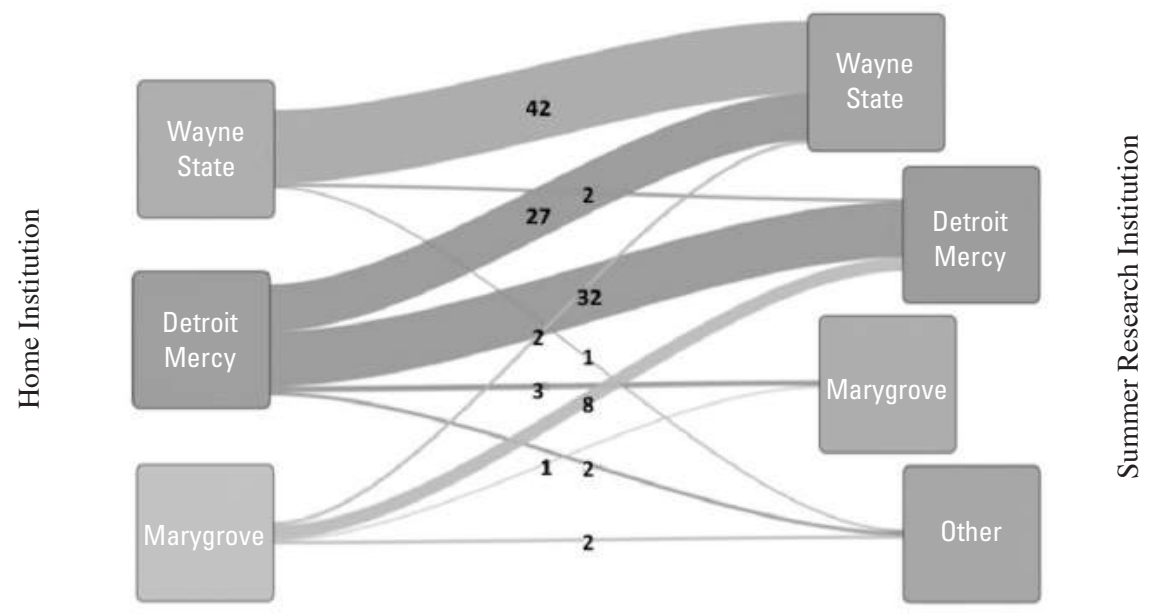

Note: Numbers reflect the frequency of students who followed the specific path between home institution and research institution. 
ing the ReBUILDetroit summer research experiences were (1) gains in thinking and working like a scientist, (2) personal achievements related to research work, (3) improvements in research and presentation skills, (4) changes in attitudes or behaviors as a researcher, and (5) perceived quality of overall research experience (see Table 2).

After one summer of research, ReBUILDetroit Scholars reported significant gains across all five dimensions of science identity and self-efficacy (see Figure 4). Scholars rated their research experiences highly, such that they exceeded 75 percent on all five dimensions of the URSSA quality scales. Furthermore, the students from the first cohort $(\mathrm{N}=51)$ showed small but significant increases across all five dimensions after their second summer research experience ( $p<0.05$; see Figure 4$)$. The majority of scholars (65 percent) chose to remain with the same research mentor for the second summer, even when offered the opportunity to transfer to a new laboratory. Scholars therefore valued the opportunity for prolonged experience within a single research group over variation and exploration of a new area.

TABLE 2. Formation of Science Identity and Self-Efficacy Scale Scores Derived from URSSA Data

\begin{tabular}{|c|c|}
\hline Scale & URSSA items \\
\hline $\begin{array}{l}\text { Gains in thinking and working like a scientist: } \\
\text { Application of knowledge to research work. } \\
\text { Q1. How much did you gain in the following } \\
\text { areas as a result of your most recent research } \\
\text { experience? }\end{array}$ & $\begin{array}{l}\text { Q1.1 Analyzing data for patterns. } \\
\text { Q1.2 Figuring out the next step in a research project. } \\
\text { Q1.3 Problem solving in general. } \\
\text { Q1.4 Formulating a research question that can be answered with data. } \\
\text { Q1.5 Identifying limitations of research methods and designs. } \\
\text { Q1.6 Understanding the theory and concepts guiding my research project. } \\
\text { Q1.7 Understanding the connections among scientific disciplines. } \\
\text { Q1.8 Understanding the relevance of research to my coursework. }\end{array}$ \\
\hline $\begin{array}{l}\text { Personal gains related to research work. } \\
\text { Q2. How much did you gain in the following } \\
\text { areas as a result of your most recent research } \\
\text { experience? }\end{array}$ & $\begin{array}{l}\text { Q2.1 Confidence in my ability to contribute to science. } \\
\text { Q2.2 Comfort in discussing scientific concepts with others. } \\
\text { Q2.3 Comfort in working collaboratively with others. } \\
\text { Q2.4 Confidence in my ability to do well in future science courses. } \\
\text { Q2.5 Ability to work independently. } \\
\text { Q2.6 Developing patience with the slow pace of research. } \\
\text { Q2.7 Understanding what everyday research work is like. } \\
\text { Q2.8 Taking greater care in conducting procedures in the lab or field. }\end{array}$ \\
\hline $\begin{array}{l}\text { Gains in research and presentation skills. } \\
\text { Q3. How much did you gain in the following } \\
\text { areas as a result of your most recent research } \\
\text { experience? }\end{array}$ & $\begin{array}{l}\text { Q3.1 Writing scientific reports or papers. } \\
\text { Q3.2 Making oral presentations. } \\
\text { Q3.3 Defending an argument when asked questions. } \\
\text { Q3.4 Explaining my project to people outside my field. } \\
\text { Q3.5 Preparing a scientific poster. } \\
\text { Q3.6 Keeping a detailed lab notebook. } \\
\text { Q3.7 Conducting observations in the lab or field. } \\
\text { Q3.8 Using statistics to analyze data. } \\
\text { Q3.9 Calibrating instruments needed for measurement. } \\
\text { Q3.11 Understanding journal articles. } \\
\text { Q3.12 Conducting database or internet searches. } \\
\text { Q3.13 Managing my time. }\end{array}$ \\
\hline $\begin{array}{l}\text { Changes in attitudes or behaviors as a researcher. } \\
\text { Q4. During your research experience how much } \\
\text { did you: }\end{array}$ & $\begin{array}{l}\text { Q4.1 Engage in real-world science research. } \\
\text { Q4.2 Feel like a scientist. } \\
\text { Q4.3 Think creatively about the project. } \\
\text { Q4.4 Try out new ideas or procedures on your own. } \\
\text { Q4.5 Feel responsible for the project. } \\
\text { Q4.6 Work extra hours because you were excited about the research. } \\
\text { Q4.7 Interact with scientists from outside your school. } \\
\text { Q4.8 Feel a part of a scientific community. }\end{array}$ \\
\hline $\begin{array}{l}\text { Perceived quality of overall research experience } \\
\text { Q5. Please rate the following: }\end{array}$ & $\begin{array}{l}\text { Q5.1 My working relationship with my research mentor. } \\
\text { Q5.2 My working relationship with research group members. } \\
\text { Q5.3 The amount of time I spent doing meaningful research. } \\
\text { Q5.4 The amount of time I spent with my research mentor. } \\
\text { Q5.5 The advice my research mentor provided about careers or graduate school. }\end{array}$ \\
\hline
\end{tabular}


FIGURE 4. Data on Student Growth Related to Science Identity and Self-Efficacy as a Result of the ReBUILDetroit Program and the Summer Research Experience (SRE)

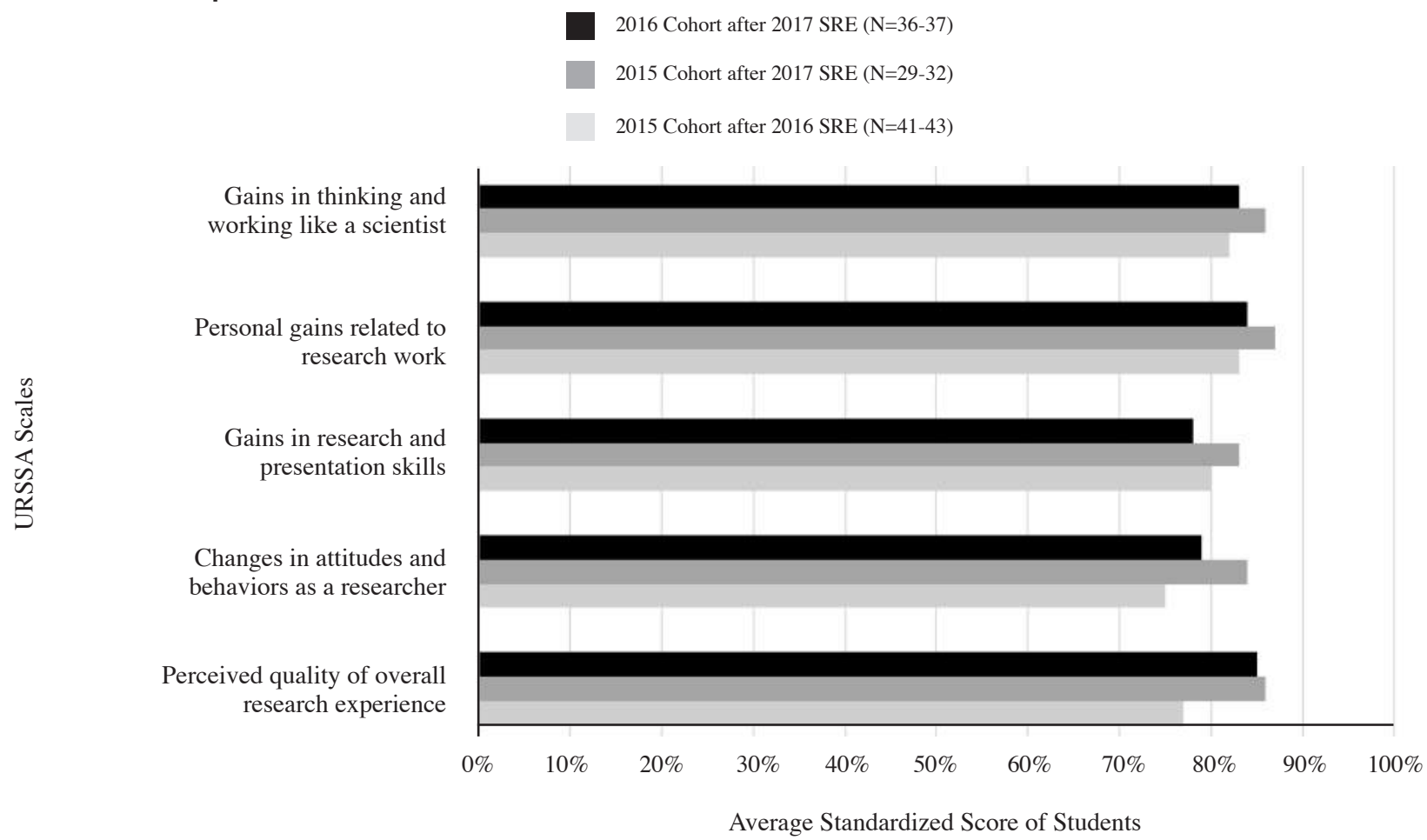

Note: Raw data were collected using an adapted version of the URSSA instrument (Weston and Laursen 2015). Scales were developed by aggregating items from the URSSA instrument as described in the text and Table 2. Data are presented as frequency distributions of students' perceptions of gain. Different vectors have different response options, following the response options used in the original URSSA measure. Values for the number of students vary slightly for each scale as a result of insufficient responses to individual questions from some participants.

\section{Qualitative Validation of Outcomes}

Focus group interviews were used to gain additional insight into the student perspective of ReBUILDetroit's mentored research experiences. The findings confirmed that students valued the relationships they formed with their faculty mentors, the extended scientific learning opportunities, and the process for mentor pairing. One student said:

I would say my relationship with (mentor name) is excellent. We see eye to eye every single time. If she has an issue with what I'm doing in the lab, then she brings it up to me in a respectful way but still in a way that lets me see that I messed up somewhere so I need to fix it. She helps me take steps necessary to fix it. I've only had positive experiences with her.

Although that is the insight of a single individual, it reflects a sentiment that was voiced repeatedly during the focus group interviews. The overall quality of the mentormentee interactions was critical to program success, as it led students to elect to continue with mentored research.

Almost unanimously, students included their research mentors as part of the support network they felt they gained from the ReBUILDetroit program. The majority of students described highly satisfying relationships with their mentors. Another student said:

With my mentor, I would keep the way he sees learning. He'll give us the basics of what we need to do in an experiment. And then he'll let us have full rein of the experiment-like, everything from the design, how we approach the next step.

Scholars talked excitedly about the research they were doing with their mentors and how their lab work allowed them to contextualize and integrate it with course-based learning within their majors. One student said:

I feel like I have learned so much more working in my lab than I had in my classes, so much more. And that is why I get more excited about it because the fact that this is what I am going to be able to do once I leave-even throughout the rest of undergrad and grad school. I am going to be able to work in a lab and actually do this stuff. And that is what I really like about BUILD, it helped me find that passion.

Scholars also highly valued the pairing process that allowed them to meet several faculty members. The pairing event 
displayed for the scholars different types of scientific projects that were available and the diverse approaches of faculty toward mentoring.

I liked the interview process you have at the beginning before you start your summer research because you get to talk to several different individuals. And BUILD helps you set up connections with them so you don't have to do it all on your own-like, email these people and find them all on your own. That's helpful.

Multiple comments echoed the sentiment that building relationships with mentors was a highlight of the year. Taken together, the qualitative outcomes from the focus groups mirrored the data from surveys and revealed that students felt prepared to enter mentored research at the end of their first year in ReBUILDetroit; the scaffolded structure of the program allowed them to seamlessly transition into mentored research; and the research experience added perspective relative to academic and career interests.

\section{Discussion}

Research experiences and the mentor-mentee relationship involved are of particular importance for career progression of trainees in biomedical disciplines (Boyd and Wesemann 2009; Chopin 2002; Dolan and Johnson 2010; Eagan et al. 2013; Hurtado et al. 2009). Most scientists can trace their careers back to specific individuals who shaped their perspective on their field and set them on their career trajectory. In the sciences, this process often starts with joining a research group. Entering research changes a student's approach to science and develops a positive science identity and self-efficacy that supports continuation within the field and academic success (Haeger and Fresquez 2016; Hurtado et al. 2009). The ReBUILDetroit program is designed to help students make this transition in an intentional environment, helping to place students successfully with research mentors and encouraging them to take full advantage of the opportunities available to them in college.

Many undergraduates have difficulty finding quality mentored research experiences, even when a culture of undergraduate research exists on campus (Aikens et al. 2017; Morales, Grineski, and Collins 2016). Students are often left to their own devices to find undergraduate research experiences and mentors. Students with high levels of social capital effectively navigate this process, whereas other students, especially first-generation college students or those from underrepresented backgrounds, may fare less well (Aikens et al. 2016; Morales, Grineski, and Collins 2017). An additional potential barrier has been highlighted in studies that found bias in how faculty respond to emails from students seeking research opportunities based on the ethnicity and gender reflected in specific names (Milkman, Modupe, and Chugh 2015).
A scaffolded entry into mentored research, including the speed-pairing process, provides a time-efficient opportunity to help students overcome barriers to identifying a mentor and joining a research group. Coaching in advance of the pairing event better prepares students to successfully navigate the placement process. By the simple metrics of efficiency and agency, speed-pairing is highly effective. Faculty can spend an hour at the event and meet several students who are interested in their work, and students can meet multiple faculty members and explore the breadth of their options. In the case of a consortium-based program like ReBUILDetroit, this process creates opportunities for the scholars to join research labs on partner campuses (Morales et al. 2016). Although data are sparse for years prior to ReBUILDetroit, it was relatively uncommon for students from Marygrove College or Detroit Mercy to seek out research experiences at WSU. An additional hallmark of successful research pairings is the number of students who choose to continue their undergraduate research with the same mentor in subsequent years, evidence that the speed-pairing process is intentional in matching mentor and mentee interests and that productive relationships form as a result. Such relationships not only contribute to the ReBUILDetroit Scholars' perceived gains and quality of research, as measured by URSSA, but also are essential for the scholars to identify as part of a community of scientists and develop as independent scientists.

The URSSA outcomes show tremendous growth in the ReBUILDetroit Scholars' perceptions of science identity and self-efficacy after the first summer of mentored research. Such gains in self-assessment of science identity and self-efficacy are reproducible from year to year. The second summer research experience does not differ programmatically for continuing scholars; however, the data reveal that the second summer of research leads to smaller but significant increases in perception of gains in science identity and self-efficacy. By the second year, the scholars have sufficient experience to take advantage of the research opportunity. One might argue from these data that a single summer experience may be sufficient for undergraduate students to develop solid skills such as understanding the theory and concepts guiding their research (dimension 1), being comfortable discussing scientific concepts with others (dimension 2), or working with computers (dimension 3). However, in the second and third years, students learn other aspects of being a scientist that are measured by dimensions in URSSA not assessed in this study of first-year students (e.g., attending conferences, presenting posters or making presentations about their research, and intentions to enroll in graduate degree programs). Going forward, URSSA questions about more senior level skills related to publications, awards, and proposal writing will be used to track the advanced research skills and awareness obtained through prolonged research exposure. It is believed that this interpretation supports 
the benefits of extended mentored research experiences that lead to greater skills development and a deeper understanding of research projects. Linn called for additional study on the benefits of undergraduate research experiences (Linn et al. 2015). Open questions regarding requisite dosage, psychosocial benefits from peer and near-peer interactions, and the importance of nonlaboratory activities that support research experiences must all be answered to fully understand how research experiences impact student development.

The question of how to reliably measure the quality of an undergraduate research experience is still unanswered. Two instruments are often used. The Summer Undergraduate Research Experience Survey (Lopatto 2004) focuses principally on program elements, whereas the URSSA survey (Weston and Laursen 2015) emphasizes perceptions and attitudes. Neither instrument fully captures the impact of research experiences nor addresses why some students report greater gains than others. Therefore, consideration is being given to scale scores that bin questions related to common themes. These themes align with those that the original creators of URSSA used to categorize items. A deeper look at how different students develop as researchers and what practices lead to that development is still important. If such measures can be developed and validated it will be easier to study the impact of individual elements of research experiences, such as the mechanism of pairing students with mentors or the impact of mentor training on the overall quality of the undergraduate research experience.

It is important to remember that the ReBUILDetroit program focuses on a scaffolded first-year curriculum; the speed-pairing process and resulting mentored research experience are two elements of an integrated program that involves several curricular and extracurricular interventions (see Figure 1). Given the symbiotic relationship of the interventions received by these students, it is not possible to specifically dissect the impact of individual elements within the context of the scholars' perceptions of science identity and persistence in undergraduate STEM careers. Thus, the progression of the ReBUILDetroit Scholars' sense of scientific identity and persistence in undergraduate STEM fields must be viewed as part of the intervention across the entire spectrum of activities. Nevertheless, the ReBUILDetroit model of scaffolding the mentored research experience, including the speed-pairing to match undergraduates with research mentors, can be incorporated into campus research programs with relative ease.

\section{Acknowledgments}

The authors thank the following participants in ReBUILDetroit's first-year curriculum, speed-pairing process, collection of data, and/or securing of funding for this study: Kristen Abraham, Stephanie Conant, Kiana
Daniels, Jonathan Finkel, Jacob Kagey, Gary Kuleck, Matt Mio, John Powell, Elizabeth Roberts-Kirchhoff, Steven Scribner, Katherine Snyder, Victoria Straub, Jennifer Tabb, Joshua Thompson, Kathleen Walker, Sally Welch, and Li-hsuan Yang. Work reported in this publication was supported by the National Institutes of Health Common Fund and Office of Scientific Workforce Diversity under three linked awards, RL5GM118981, TL4GM118983, and 1UL1GM118982, administered by the National Institute of General Medical Sciences.

\section{References}

Aikens, Melissa L., Melissa M. Robertson, Sona Sadselia, Keiana Watkins, Mara Evans,Christopher R. Runyon, Lillian T. Eby, and Erin. L. Dolan. 2017. "Race and Gender Differences in Undergraduate Research Mentoring Structures and Research Outcomes." CBE-Life Sciences Education 16(2): 1-12. doi: 10.1187/cbe.16-07-0211

Aikens, Melissa L., Sona Sadselia, Keiana Watkins, Mara Evans, Lillian T. Eby, and Erin L. Dolan. 2016. "A Social Capital Perspective on the Mentoring of Undergraduate Life Science Researchers: An Empirical Study of Undergraduate-Postgraduate-Faculty Triads." CBE-Life Sciences Education 15(2): 1-15. doi: $10.1187 /$ cbe.15-10-0208

Andreoli, Jeanne M., Andrew Feig, Steven Chang, Sally Welch, Ambika Mathur, and Gary Kuleck. 2017. "A Research-Based Inter-Institutional Collaboration to Diversify the Biomedical Workforce: ReBUILDetroit." BMC Proceedings 11(Suppl 12): 23. doi: 10.1186/s12919-017-0093-6

Boyd, Mary K., and Jodi L. Wesemann, eds. 2009. Broadening Participation in Undergraduate Research. Washington, DC: Council on Undergraduate Research.

Branchaw, Janet L., Christine Pfund, and Raelyn Rediske. 2010. Entering Research. New York: Freeman.

Brink, Pamela J. 1995. "Learning How to Do Research Requires a Mentor." Western Journal of Nursing Research 17: 351-352. doi: 10.1177/019394599501700401

Chang, Mitchell J., M. Kevin Eagan, Monica H. Lin, and Sylvia Hurtado. 2011. "Considering the Impact of Racial Stigmas and Science Identity: Persistence among Biomedical and Behavioral Science Aspirants." Journal of Higher Education 82: 564-596. doi: $10.1353 /$ jhe. 2011.0030

Chopin, Suzzette F. 2002. "Undergraduate Research Experiences: The Translation of Science Education from Reading to Doing." Anatomical Record 269: 3-10. doi: 10.1002/ar.10058.

Committee on Underrepresented Groups and the Expansion of the Science and Engineering Workforce Pipeline. 2011. Expanding Underrepresented Minority Participation: America's Science and Technology Talent at the Crossroads. Washington, DC: National Academy of Science. doi: 10.17226/12984

Cupples, Sandra A. 1999. "Selection, Care, and Feeding of a Research Mentor." Alzheimer Disease and Associated Disorders 13(Suppl 1): S22-28. doi: 10.1097/00002093-199904001-00007

Dolan, Erin L., and Deborah Johnson. 2010. "The Undergraduate-Postgraduate-Faculty Triad: Unique Functions and Tensions 
Associated with Undergraduate Research Experiences at Research Universities." CBE-Life Sciences Education 9(4): 543-553. doi: 10.1187/cbe.10-03-0052

Eagan, M. Kevin, Jr., Sylvia Hurtado, Mitchell J. Chang, Gina A. Garcia, Felisha A. Herrera, and Juan C. Garibay. 2013. "Making a Difference in Science Education: The Impact of Undergraduate Research Programs." American Educational Research Journal 50: 683-713. doi: 10.3102/0002831213482038

Guse, Jennifer, Eva Schweigert, Gerhild Kulms, Ines Heinen, Claudia Martens, and Andreas H. Guse. 2016. "Effects of Mentoring Speed Dating as an Innovative Matching Tool in Undergraduate Medical Education: A Mixed Methods Study." PLOS ONE 11(2): e0147444. doi: 10.1371/journal.pone.0147444

Haeger, Heather, and Carla Fresquez. 2016. "Mentoring for Inclusion: The Impact of Mentoring on Undergraduate Researchers in the Sciences." CBE-Life Sciences Education 15(3): 1-9. doi: 10.1187/cbe.16-01-0016

Handelsman, Jo, Sarah Miller Lauffer, Christine Maidl Pribbenow, and Christine Pfund. 2009. Entering Mentoring. Blue Mounds, WI: Itchy Cat Press.

Hurtado, Sylvia, Damani White-Lewis, and Keith Norris. 2017. "Advancing Inclusive Science and Systemic Change: The Convergence of National Aims and Institutional Goals in Implementing and Assessing Biomedical Science Training." BMC Proceedings 11(Suppl 12): 17. doi: 10.1186/s12919-017-0086-5

Hurtado, Sylvia, M. Kevin Eagan, Minh C. Tran, Christopher B. Newman, Mitchell J. Chang, and Paolo Velasco. 2011. “We Do Science Here': Underrepresented Students' Interactions with Faculty in Different College Contexts." Journal of Social Issues 67: 553-579. doi: 10.1111/j.1540-4560.2011.01714.x

Hurtado, Sylvia, M. Kevin Eagan, Nolan L. Cabrera, Monica H. Lin, Julie Park, and Miguel Lopez. 2008. "Training Future Scientists: Predicting First-Year Minority Student Participation in Health Science Research." Research in Higher Education 49: 126-152. doi: 10.1007/s11162-007-9068-1

Hurtado, Sylvia, Nolan L. Cabrera, Monica H. Lin, Lucy Arellano, and Lorelle L. Espinosa. 2009. "Diversifying Science: Underrepresented Student Experiences in Structured Research Programs." Research in Higher Education 50: 189-214. doi: 10.1007/s11162-008-9114-7

Kuh, George D., Jillian Kinzie, Jennifer A. Buckley, Brian K. Bridges, and John C. Hayek. 2006. What Matters to Student Success: A Review of the Literature. Washington, DC: National Postsecondary Education Cooperative.

Kurré, Jennifer, Eva Schweigert, Gerhild Kulms, and Andreas H Guse. 2014. "Speed Mentoring: Establishing Successful Mentoring Relationships." Medical Education 48: 1131. doi: 10.1111/ medu. 12555

Linn, Marcia C., Erin Palmer, Anne Baranger, Elizabeth Gerard, and Elisa Stone. 2015. "Education. Undergraduate Research Experiences: Impacts and Opportunities." Science 347: 1261757. doi: $10.1126 /$ science.1261757

Lopatto, David. 2004. "Survey of Undergraduate Research Experiences (SURE): First Findings." Cell Biology Education 3: 270-277. doi: 10.1187/cbe.04-07-0045
Lopatto, David. 2007. "Undergraduate Research Experiences Support Science Career Decisions and Active Learning." CBE-Life Sciences Education 6(4): 297-306. doi: 10.1187/cbe.07-06-0039

Malcom, Shirley, and Michael Feder. 2016. Barriers and Opportunities for 2-Year and 4-Year Stem Degrees: Systemic Change to Support Students' Diverse Pathways. Washington, DC: National Academies Press. doi: 10.17226/21739

Milkman, Katherine L. , Modupe Akinola, and Dolly Chugh. 2015. "What Happens Before? A Field Experiment Exploring How Pay and Representation Differentially Shape Bias on the Pathway into Organizations." Journal of Applied Psychology 100: 1678-1712. doi: 10.1037/ap10000022.supp

Moed, Berton R. 2012. "Mentoring: The Role of a Mentor and Finding One." Journal of Orthopaedic Trauma 26(Suppl 1): S23-24.

Morales, Danielle X., Sara E. Grineski, and Timothy W. Collins. 2016. "Influences on Faculty Willingness to Mentor Undergraduate Students from Another University as Part of an Interinstitutional Research Training Program." CBE-Life Sciences Education 15(3): 1-15. doi: 10.1187/cbe.16-01-0039

Morales, Danielle X., Sara E. Grineski, and Timothy W. Collins. 2017. "Increasing Research Productivity in Undergraduate Research Experiences: Exploring Predictors of Collaborative Faculty-Student Publications." CBE-Life Sciences Education 16(3): 1-9. doi: 10.1187/cbe.16-11-0326

Packard, Becky W. L. 2015. Successful Stem Mentoring Initiatives for Underrepresented Students: A Research-Based Guide for Faculty and Administrators. Sterling, VA: Stylus.

Pfund, Christine, Angela Byars-Winston, Janet Branchaw, Sylvia Hurtado, and Kevin Eagan. 2016. "Defining Attributes and Metrics of Effective Research Mentoring Relationships." AIDS and Behavior 20(Suppl 2): 238-248. doi: 10.1007/s10461-016$1384-\mathrm{z}$

Pfund, Christine, Kimberly C. Spencer, Pamela Asquith, Stephanie C. House, Sarah Miller, and Christine A. Sorkness. 2015. "Building National Capacity for Research Mentor Training: An Evidence-Based Approach to Training the Trainers." CBE-Life Sciences Education 14(2): ar24. doi: 10.1187/cbe.14-10-0184

Prunuske, Amy J., Janelle Wilson, Melissa Walls, and Benjamin Clarke. 2013. "Experiences of Mentors Training Underrepresented Undergraduates in the Research Laboratory." CBE-Life Sciences Education 12: 403-409. doi: 10.1187/cbe.13-02-0043

Prunuske, Amy J., Janelle Wilson, Melissa Walls, Hannah Marrin, and Benjamin Clarke. 2016. "Efforts at Broadening Participation in the Sciences: An Examination of the Mentoring Experiences of Students from Underrepresented Groups." CBE-Life Sciences Education 15(3): ar26. doi: 10.1187/cbe.16-01-0024

Ramirez, Julio J. 2012. "The Intentional Mentor: Effective Mentorship of Undergraduate Science Students." Journal of Undergraduate Neuroscience Education 11(1): A55-63.

Sorkness, Christine A., Christine Pfund, Pamela Asquith, and Marc K. Drezner. 2013. "Research Mentor Training: Initiatives of the University of Wisconsin Institute for Clinical and Translational Research." Clinical and Translational Science 6: 256-258. doi: $10.1111 /$ cts.12085

Fall 2018 | Volume 2 | Number 1 | 13 
Thiry, Heather, and Sandra L Laursen. 2011. "The Role of Student-Advisor Interactions in Apprenticing Undergraduate Researchers into a Scientific Community of Practice." Journal of Science Education and Technology 20: 771-784. doi: 10.1007/ s10956-010-9271-2

Weston, Timothy J., and Sandra L. Laursen. 2015. "The Undergraduate Research Student Self-Assessment (URSSA): Validation for Use in Program Evaluation." CBE-Life Sciences Education 14(3): 1-10. doi: 10.1187/cbe.14-11-0206

Wilson, Denise, Diane Jones, Fraser Bocell, Joy Crawford, Mee Joo Kim, Nanette Veilleux, Tamara Floyd-Smith, Rebecca Bates, and Melani Plett. 2015. "Belonging and Academic Engagement among Undergraduate STEM Students: A Multi-Institutional Study." Research in Higher Education 56: 750-776. doi: 10.1007/s11162-015-9367-x

\section{Andrew L. Feig}

Wayne State University, afeig@chem.wayne.edu

Farron McIntee is the research enrichment coordinator for the ReBUILDetroit program and an education professional skilled in neurochemistry, molecular biology, and pathology. Her work at Wayne State University (WSU) focuses on curriculum redesign and institutional innovation associated with enhancing undergraduate research training and student achievement, especially for underrepresented students.

Kendra R. Evans is an associate professor of chemistry and biochemistry at the University of Detroit Mercy. Her research interests include liquid chromatography-mass spectrometry-based pesticide analyses in tissue and water samples, as well as the development, implementation, and assessment of course-based undergraduate research experiences. Evans serves as the vice president of the Association of Analytical Chemists (ANACHEM) and as the research enrichment core leader at the University of Detroit Mercy for the ReBUILDetroit Program.

Jeanne M. Andreoli is an associate professor emerita and former chair of the Division of Natural Sciences and Mathematics at Marygrove College. She continues her work as the director of the Institutional Development Core and grant writer for the ReBUILDetroit program at the University of Detroit Mercy. Her research interests are grounded in the scholarship of teaching and learning, including learning theory, pedagogy, and assessment. She has worked closely with the Association of American Colleges \& Universities (AAC\&U) and Project Kaleidoscope (PKAL) to scale-up and institutionalize efforts to transform undergraduate STEM learning environments, primarily through facilities planning, faculty development, leadership development, and curricular innovation.

Abigail J. Fusaro is a former assistant professor of biology at Marygrove College, where she served as Marygrove's ReBUILDetroit Research Coordination Network representative. Her research focuses on the application of molecular tools to questions in traditional ecology, evolution, and organismal biology-particularly those patterns and processes controlling dispersal, community establishment, population maintenance, and microevolution in disjunct and disturbed aquatic habitats. She also has interests in pedagogy and mentoring students from underrepresented populations.

Melanie Hwalek is the CEO of SPEC Associates, the external evaluator for ReBUILDetroit, and assistant professor in the Department of Psychology at Michigan State University (MSU). In addition to evaluating human service and educational programs through SPEC Associates, she teaches evaluation management in the MSU master's and certificate programs in program evaluation. She holds a Certified Evaluator Designation from the Canadian Evaluation Society. Her research interests are in psychometrics and the retrospective pretest methodology.

Ambika Mathur is a professor of pediatrics, dean of the Graduate School, and associate provost for scientific training workforce development and diversity at WSU. She is deeply committed to the advancement of all aspects of training from high school to postdoctoral levels. She is coprincipal investigator of the ReBUILDetroit program and the NIH-funded BEST Program at WSU. She has worked closely with the leadership at national organizations like the AAMC and the Council of Graduate Schools and with the deans of WSU's 12 schools and colleges toward improving diversity and inclusion in higher education and the implementation of evidence-based practices in graduate education.

Andrew L. Feig is a chemistry professor, associate dean of the Graduate School at Wayne State University, and director of the Research Enrichment Core of the ReBUILDetroit program. He has 20 years of experience working with and mentoring graduate and undergraduate students. His laboratory works in the area of microbial biochemistry, molecular biology, chemical biology, and the molecular life sciences. He also works in professional development for students and faculty, institutional transformation, longitudinal data analytics related to educational and career outcomes, and issues related to improving diversity and inclusion in STEM and higher education. 